\title{
0 imposto sobre dividendos no Supremo Tribunal Federal e no Congresso
}

Nenhum golpe mais assustador poderia ferir os preceitos constitucionaes, attinentes á distribuição das rendas entre a União e os Estados, que o recente julgado, pelo qual o Supremo Tribunal Federal proclamou a competencia daquella para tributar os dividendos das companhias industriaes com séde no territorio destes ou que n'elles exercerem suas industrias.

A esta perigosissima conclusão chegaram os egregios juizes desse Tribunal, por meio de raciocinio, em cada uma de cujas premissas se registra a inversão das noções, mais universalmente acceitas, da Economia Politica e da Sciencia das Finanças, sobre o que é da essencia dos impostos, como sobre os caracteres que dominam a respectiva classificação; e no qual não se guardou, ainda, o devido acatamento ás mais salutares regras da Hermeneutica Juridica.

Não nos tivesse dado esse eminente Conselho de Juizes tão frequentes demonstrações de quão facil the é volver de doutrinas mal inspiradas, e apparelhar-nos- 
iamos, desde já, para contemplar a mais absoluta subversão do regimen tributario creado pela Constituição.

E esta preoccupação assaltará, de certo, todos os que concederem alguma attenção aos commentarios inspirados pelos motivos da decisão alludida.

Conhecendo de um pedido de restituição de impostos sobre dividendos, formulado, em acção competente, por alguns bancos do Estado da Bahia, concluiu o Supremo Tribunal que esses impostos são da natureza daquelles que competem cumulativamente á União e aos Estados, nos termos do art. I 2 da Constituição; baseado este dispositivo nos seguintes considerandos, que iremos acompanhando da critica que nos suggerem:

«Considerando que o imposto sobre dividendos, cobravel para a União em todo o territorio nacional, desde a vigencia daquellas disposições legislativas (I), não póde, por sua propria natureza, (?) ser havido como de industrias e profissões, desde que este recáe sobre o exercicio de uma industria ou profissão, ao passo que aquelle incide sobre o lucro liquido correspondente ao numero de acçoes, onerando, assim, cada um dos accionistas, embora seja pago directamente pela companhia, attenta a diffculdade pratica de cobral-o de cada possuidor de taes acções;

Considerando que o accionista, ao solver esse imposto, não paga pela in-

(1) Refere-se ás leis orçamentarias de 1897 e dos annos seguintes, que ampliaram ás companhias com séde nos Estados o imposto sobre dividendos, cobrado, até então, desde 1891, sómente ás estabelecidas no Districto Federal. 
dustria ou profissão que exercita no seio da companhia de que faz parte, mas pelo lucro do capital nella empregado, visto como as sociedades anonymas, como é corrente, são antes sociedades de capitaes que de pessôas.»

Estes dous fundamentos, que se podiam reduzir a um, dão como certo que o imposto de industrias e profissões recáe sobre o exercicio dellas, emquanto o de dividendos affecta o capital dos accionistas.

Em multiplas censuras incorre, logo ao primeiro exame, esta premissa de julgado.

Antes de tudo, não é exacto que o imposto de industrias e profissões seja pago pelo exercicio dellas, ou que recáia sobre tal exercicio; não teria isso significação economica.

Recáe, na realidade, sobre as vantagens ou proveitos, real ou presumidamente, auferidos das industrias e profissões.

Tanto não é cobrado pelo simples exercicio da industria, que, por toda parte onde existe, onera industrias similares com taxas differentes e as mesmas industrias com taxas tambem diversas, conforme a importancia do logar em que são exercidas e do predio em que se installam; assim como poupa, ás vezes, pequenas industrias de resultados insignificantes (2).

Não são tributadas as industrias senão pelo fundamento de serem uma fonte de redditos para os que as exercem, ou pelo de que offerecem aos esforços individuaes e ao capital, um resultado que comporta uma contribuição para os serviços do Estado.

(2) Vide o Regulamento n. 9.870, de I7 de Fevereiro de 1888 , art. $5 .^{\circ}$, e, no mesmo sentido, o Regulamento n, 2.792 de II de Janeiro de 1898 , art. $50^{\circ}$ 
Existem applicações da actividade individual, exercitadas habitualmente, em condições semelhantes ás industriaes, que não são attingidas por um imposto, porque não deixam aos respectivos agentes vantagens apreciaveis.

O imposto procura sempre uma parte dos rendimentos.

Nunca se procurou applicar o imposto ás funcções ou aos actos de que não provenha um resultado pecuniario ou a isso equivalente; aos phenomenos sociaes que não tenham valor economico.

$\mathrm{E}$ esse caracteristico, essencial ao imposto, de procurar a renda, accentúa-se muito mais nos impostos de industrias e profissões.

Já tivemos occasião de dizel-o, em publicação feita no Fornal do Commercio, a 3 de Janeiro deste anno, invocando então a auctoridade dos que, com proficiencia mais indiscutivel, têm doutrinado sobre a materia.

Entre elles citámos o erudito professor Graziani, da Universidade de Siena, que, em suas excellentes Instituzioni di Scienza delle Finanze, ensina á pag. 462: "L'imposto industriale colpisce il prodstto netto delle industrie, nel senso più largo della parola, cioé il profitto delle imprese produttive.»

«IL A POUR BASE, EN EFFET, LA MOYENNE SUPPOSÉE DES BÉNÉFICES QUE CHAQUE CATÉGORIE DE NEGOCIANTS PEUT RAISONNABLEMENT OBTENIR DANS DES CONditions DETERminées d'EXPloitation.» (Leroy Beaulieu, Sciences des Finances, vol. I.', pag. 402) (3). criptor:

(3) Referindo-se ainda a este imposto na França, continúa esse es-

"DEPUIS I79I jusqu'à l'heure actuelle, il y a eu un éffort constant pour rendre l'impôt des patentes de plus en plus proportionel aux benéfices du contribuable.» 
Não tem, por consequencia, o bafejo da sciencia a distincção que faz o accórdam entre o imposto de industrias e profissões-affectando o exercicio destas-e o imposto sobre dividendos-incidindo sobre lucros liquidos; ao contrario, considerado o objecto que gravam, os dous identificam-se em absoluto.

Ora, se é pela virtude caracteristica de gravarem os lucros liquidos dos accionistas, que se attribúe á União a competencia para os impostos sobre dividendos, cumpre que tal competencia se lhe outorgue tambem, no que diz respeito a todo e qualquer imposto de industrias e profissões, que a Constituição, entretanto, adjudicou, privativamente aos Estados.

Egualmente insustentavel é o accórdam quando diz que o imposto sobre dividendos não affecta o lucro industrial e, sim, o lucro ou renda do capital do accionista.

Faz aqui a respeitavel sentença uma deploravel confusão entre proveitos industriaes e renda do capital, cousas accentuadamente distinctas em Economia Politica e em Sciencia das Finanças, como nas leis de todas as nações cultas (4).

Os dividendos das companhias são proveitos industriaes, renda mixta resultante do capital e do trabalho.

A renda do capital chama-se interesse ou juro; provém do capital dado a mutuo.

(4) Em todos os paizes onde existe o imposto sobre a renda, figuram, em classes distinctas, o imposto sobre os proveitos industriaes, comprehendendo os dividendos distribuidos pelas companhias industriaes, e o imposto sobre a renda do capital, que comprehende, apenas, os interesses, ou o juro, do capital dado a mutuo.

Assim, na. Inglaterra, na Italia na Austria, em Portugal e em outros paizes. 
Melhor do que nós, e eloquentemente como não o poderiamos fazer, patenteiam esta distincção todos os economistas e financistas que consultámos.

Flora, no seu Manuale di Scienza delle Finanze (2. ${ }^{a}$ ed. Livorno, I903), ensina á pag. 356:

«La legge accetta, inoltre, la divisione del reddito, GIUSTA LA SUA NATURA ECONOMICA, in salario, interesse e profitto: ma usa una nomenclatura diversa dalla scientifica, chiamando i primi-redditi profissionali, i secondi-capitalistici e gli ultimi redditi industriali o misti.»

Depois de mostrar como a lei italiana, reguladora do imposto sobre valores moveis, faz, con maggiore precisione scientifica, a divisão das respectivas rendas, tomando por base seus tres elementos constitutivos, salario, profitto e interesse, e distribuindo por classes distinctas a renila do capital, que é a produzida pelo capital dado a mutuo, e a renda das industrias, proveniente do capital e do trabalho, na qual se comprehendem os dividendos, caracterisa nestes termos inequivocos, o interesse, ou a renda do capital:

«L'interesse è la parte del reddito che spetta, nella sua integrità, a colui che fornisce il capitale all'opera della produzione ESERCITATA A RISCHIO E PROFITTO ALTRUI.»

A pag. 325 , sob o titulo-L'imposta sul prodotto dell'industria (profitti), tinha elle dito:

«L'imposta sul prodotto dell'industria colpisce il profitto dell'intraprenditore d'industria, il quale, disponendo dei fattori produttivi (natura, lavoro, capitale) organizza concretamente la produzione 
e LA EFFETUA A PROPRIO RISCHIO E BENEFICIO.

In una progredita divisione professionale del lavoro, il profitto rappresenta unicamente il compenso per il rischio. che rimane totalmente a carico dell'intraprenditore d'industria, mentre $\mathrm{i}$ capitalisti e gli operai ricevono una quota fissa, precedentemente determinata, e che le assicura contra l'alea della produzione,

Nelle condizioni economiche attuali, però, l'intraprenditore impiega i propri capitale, sichè le legislazione positive colpiscono l'intero reddito del'intraprenditore quale capitalista e lavoratore, onde il nome di reddito misto con cui essi designano il profitto.»

Ainda no mesmo capitulo, á pag. 328, depois de registrar que tão difficil quanto a da renda do capital - é a taxação dos proveitos industriaes, consigna que, QUANTO A ESTES IMPOSTOS, AS EMPRESAS COLLECTIVAS SÃo AS MAIS ONERADAS PELA TAXa PORCENTUAL QUE GRAVA OS SEUS DIVIDENDOS.

Oronzio Quarta, no seu precioso Commento alla legge sull'imposto di richezza mobile, vol. I.", pag. I 32 , (2. ${ }^{\mathrm{a}}$ ed., Milão, I902), accentuando essa distincção, diz que $o$ art. $3 .^{\circ}$, lettra $f$, se refere exclusivamente ai redditi certi $e$ definiti dipendenti dal solo capitale, non già di redditi industriali e commerciali. E continúa:

«I DIVIDENDI E GLI STIPENDI SONO ANCHE REDDITI INDUSTRIALI E PROFISSIONALI.»

No mesmo sentido Leroy-Beaulieu, op. cit., vol. I. ${ }^{\circ}$, pag. $39 \mathrm{I}$. 
Eis aqui, portanto, expresso nos conceitos, seguros e eloquentes, de tão illustres mestres, não só que o imposto sobre os dividendos é um imposto industrial, como, ainda, que este se distingue nitidamente do imposto sobre a renda do capital.

Cawès, no seu Cours d'Économie Politique, assim se exprime: "Les revenus des particuliers ont pour origine l'interêt, les profits ou les salaires» (Vol. 2. ${ }^{\circ}$, n. I.232).

A auctoridade extraordinaria de Stuart Mill assegura-nos ainda mais nestas idéas e, consequentemente, desauctorisa a decisão que vimos apreciando.

Nos seus Principes d'Économie Politique (trad. franc. de H. Dussard et Courc. Senueil, Paris, I 824), á pag. 460, preceitúa o inexcedivel mestre:

«Toutefois, une partie seulement des gains que la possession du capital permet de faire est, à proprement parler, le prix de l'usage même du capital; c'est celle qu'une autre persone, emprutant le capital, consentira à payer.

Cette partie, qui s'appelle inter êt, est tout ce que le capitaliste gagne en s'abstenant simplement de consommer immédiatement son capital et en permettant à d'autres de s'en servir reproductivement.

La somme du profit est beaucoup plus forte que celle de l'interêt. La différence est en partie une indemnité pour les risques. En prêtant son capital on ne court que peu ou point de risques.

Mats LORSQu'on S'Engage dans DES AFFAIRES QUE L'ON FAIT Á SON PROPRE COMPTE, 
ON EXPOSE TOUJOURS LE CAPITAL À QUELQUES CHANCES DE PERTE PARTIELLE OU TOTALF, ET SOUVENT CES CHANCES SONT TRÈS GRANDES.»

«Le capital emprunté-continúa á pag. 46I-en tout, ou en partie, peut appartenir à quelqu'un qui n'entre pour vien dans les fatigues et dans les risques de la production.

En ce cas, le prêteur ou propriétaire est celui qui pratique l'absence; IL EST RÉMUNÉRÉ PAR L'NNTERÊTT QU'ON LUI PAIE; TANDIS QUE LA DIFEÉRENCE ENTRE L'INTERÊT ET LE PROFIT BRUT RÉMUNÉRE LE TRAVAIL ET LES RISQUES DE L'ENTREPRENEUR.»

Proseguindo nesta ordem de idéas, mostra o eminente economista que os lucros do commanditario, como os daquelles que, em outras especies de sociedades, fornecem os capitaes para as empresas, correndo os riscos e perigos dellas, o que se dá nas sociedades anonymas, são proveitos mixtos, SÃO RENDAS INDUSTRIAES.

Por sua vez, o notavel professor Graziani (op. cit., pag. 474), em capitulo subordinado ao titulo Imposta sugli interessi del capitale, resume, com admiravel clareza, os caracteristicos do interesse $e$ do rendimento industrial, nestas palavras:

"Mentre il profitto è un reddito originario, IMMEDIATAMENTE DOVUTO ALL'ESITO CONCRETO DELLA PRODUZIONE INDUSTRIA$\mathrm{LE}$, l'interesse è un reddito devivato, contrattuale, senza alcuna attività personale, in compenso della cessione dell'uso di una quantità di capitale, per un determinato periodo di tempo.» 


\section{$-146-$}

«E noi qui parliano dell'interesse nel senso piú ampio della parola, comprendendovi pure le annualitá, sia a termine fisso, sia vitalizio, che manifestano la medesima natura economica della retribuzione correspondente al mutuo.»

No seguimento desse capitulo, o auctorisado professor occupa-se de uma das objecções levantadas contra o proprio imposto sobre a renda do capital, objecção que pø̃e muito em relevo o erro da doutrina do accordam que impugnamos.

Essa objecção consiste em affirmar que o proprio imposto sobre os interesses ou sobre a renda do capital é injusto e importa em uma superposição ou taxação dupla, porque taes capitaes, quando emprestados, e applicados em varios objectivos, pagam já outros impostos, como o imposto sobre a propriedade immovel e o imposto industrial; que, assim, esse imposto já está incluido em outros.

Comquanto não reconheça inteira procedencia na objecção e não a julgue sufficiente para condemnar o imposto sobre a renda do capital, reconhece, todavia, o illustre financista que, em alguns casos, esse imposto importa em uma tributação dupla.

Pois bem: a doutrina do accordam estabelece o principio contrario. Confundindo a renda do capital com a renda industrial, entende que a taxação dos dividendos auferidos directamente das industrias por aquelles que as exercitam, correndo-lhes os riscos e participando da direcção, pela escolha dos administradores, por elles retribuidos, pelas deliberações em assembléa geral, já relativamente a operações e actos ainda a realisar, já relativas aos actos passados, que examinam e julgam, é um imposto distincto, que affecta 
ou grava uma fonte muito differente dos proveitos industriaes!

Antes de passarmos adeante, vamos transcrever um trecho frisantissimo com que a auctoridade irrecusavel de Leroy Beaulieu fulmina o julgado do Supremo Tribunal, repellindo a distincção arbitraria que elle consagra.

A' pag. 4 I 7 (vol. I) do seu magnifico Traité de la Science des Finances, diz o erudito economista:

"Il importe de détruire un préjugé qui est trop répandu; on crôit souvent que les valeurs mobilières ne supportent pas d'autres taxes que celles qui en reduisent ostensiblement, les dividendens et les interêts annuels, (sempre a distincção entre dividendos e interesses).

Il en est autrement: CES VALEURS DITES MOBILIÈRES SONT DE SIMPLES TITRES RÉPRÉSENTATIFS DE PARTS DANS UNE SOCIÉTÉ QUI A DÉJÀ PAYÉ UNE FOULE D'IMPÔTS; L'IMPÔT FONCIER, SI CETTE SOCIÉTÉ A DES IMMEUBLES; L'IMPÔT DES PATENTES, SI ELLE EXERCE UM COMMERCE OU UNE INDUSTRIE; LES DROITS D'ENREGISTREMENT ET DE TIMBRE SOUS LES FORMES LES PLUS VARIÉES.

L'impôt sur les revenus des valeurs mobilières est, donc, un impôt supplementaire qui s'ajoute à toutes les taxes qu'une société a dejà payées dans la même mesure que les autres contribuables» (5).

(5) CAWÈs-Op. cit., v. $2 .^{\circ}$, n. I 263 , referindo-se ao imposto sobre valores mobiliarios em França, assim se manifesta: "La vraie question est de savoir si cet impôt ne s'ajoute pas injustement aux taxes que la socićté par actions a acquitées; cette société, ayant payé l'impót foncier, l'impot des patentes: ces objections sont exactes. 
Eis, por consequencia, demonstrado com os mais acatados dogmas da sciencia, que o imposto sobre dividendos, distincto inteiramente do imposto sobre o capital, é rigorosamente um imposto industrial; um imposto mixto, como quaesquer impostos industriaes, incluido por todos os economistas na mesma classe d'estes; exactamente da mesma natureza; absolutamente identico, salvo a differença de nome, aos chamados impostos de industrias e profissões, attribuidos pela Constituição á competencia exclusiva dos Estados, e nelles comprehendido.

E demonstrado, assim, que insustentaveis são as duas primeiras razões do accordam, passemos ao exame das outras, que não são mais felizes.

\section{II}

O terceiro fundamento do accordam é concebido n'estes termos:

"Considerando que, se o accionista paga tal imposto pelo exercicio da industria ou profissão correspondente á sociedade de que é membro, não estariam sujeitos aos mesmos, nas companhias mercantis, todos os impedidos de commerciar, mas que, não obstante, podem ser accionistas dellas, (arts. $20^{\circ}$ e $3 .^{\circ}$ do Cod. Com.) isenção esta, entretanto, não admittida por lei.»

Uma grande difficuldade, desde logo, se nos depara, neste considerando; qual a de achar o nexo logico com que os eminentes signatarios do accordam prenderam, tão facilmente, uma a outra, cousas tão differentes e inspiradas em razões de ordem tão diversa. 
Formulado em outros termos, é este o raciocinio do accordam:

O imposto sobre industrias e profissões é cobrado pelo exercicio de umas e de outras;

ora, o imposto sobre dividendos abrange, ás vezes, individuos prohibidos de exercer a industria commercial;

logo, o imposto sobre dividendos não recáe sobre industrias e profissões.

A este argumento poderiamos oppôr este outro, rigorosamente da mesma natureza e de igual quilate:

O imposto de industrias e profissões pago pelas companhias recáe, em ultima analyse, sobre os accionistas; (6)

ora, entre estes pode haver alguns prohibidos de commerciar;

logo, esse imposto não recáe sobre industrias e profissōes.

Bastaria isto para revelar o valor do argumento.

Mas, prosigamos, principiando por salientar a contradicção do accordam, que, no segundo considerando, discute com a circumstancia de serem as sociedades anonymas sociedades de capitaes, em que o elemento pessoal é indifferente, e no terceiro assim se preoccupa com a qualidade pessoal dos accionistas.

Se a prohibição de commerciar, estatuida no Codigo Commercial, em relação a certas classes de individuos, fosse absoluta, nem assim o imposto de dividendos perderia o seu caracter, pela possibidade de,

(6) No seu primeiro considerando, disse o accordam, como vimos, que o imposto sobre dividendos onera cara um dos accionistas, comquanto seja pago pela companbia; o mesmo se dá com qualquer imposto de industrias e profissões. 
excepcionalmente, abranger ou apanhar taes individuos, em um ou outro caso, no exercicio da industria que lhes é vedada.

A consequencia logica, em um caso desses, seria a de que não estariam esses individuos sujeitos ao imposto; até porque admittir o contrario seria incorrer na grave contradicção de legitimar, pela cobrança do imposto, uma pratica prohibida pela lei.

Demais: nunca seria licito, por uma excepção, inutilisar os principios geraes e o systema do imposto.

Mas, a prohibição de commerciar, contida no artigo 2. do Codigo, e limitada a certas fórmas de exercer o commercio.

Sob a forma de socio de uma companhia ou sociedade anonyma, esse exercicio é permittido aos individuos enumerados no art. $2 .^{\circ}$; permissão expressa no $\operatorname{art} .3^{\circ}$

Ora, se o proprio Codigo não considerasse o accionista de uma sociedade anonyma como exercendo, de um modo especial, uma funcção de natureza commercial, não consignaria a excepção do art. $3 .^{\circ}$; porque ella seria uma funcção estranha, por inteiro, ás cogitações e aos intuitos dessa lei.

O proprio accordam fornece ainda um outro argumento contra este seu terceiro considerando e que o destróe.

No seu primeiro considerando, firmára elle o principio de que os accionistas são méros prestadores de capital, sendo os dividendos interesse, juro, renda ou premio desse capital.

Ora, o Codigo, no art. $3 \cdot^{\circ}$, considera, como commercial, a profissão habitual de dar dinheiro a premio.

Logo, os accionistas, entre os quaes os prohibidos de commerciar, exercem, segundo o accordam, a 
industria commercial; logo, o Codigo prohibe e perrnitte, ao mesmo tempo, aos comprehendidos no art. $2 .^{\circ}$, a profissão habitual de dar dinheiro a premio.

Esta conclusão absurda, a que a logica nos conduz, desfaz, portanto este fundamento do accordam.

Para que tenham incorrido em tão graves inconsequencias os espiritos esclarecidos que firmam essa decisão, é preciso que seja indefensavel a doutrina que amparam com a sua sabedoria e com o seu prestigio.

Todas as consequencias absurdas a que leva o $3 .^{\circ}$ considerando partem do erro commettido pelos illustres juizes, de considerar o imposto de industrias e profissões como objectivando o exercicio material dellas e o de dividendos, como affectando interesses do capital.

\section{III}

Não são mais convincentes os demais fundamentos do accordam cuja critica vimos fazendo. sões:

$\mathrm{O}$ quarto e o quinto enunciam-se nestas expres-

«Considerando que, no regimen tributario de que se trata, consolidado no decreto n. 9.870, de 22 de Fevereiro de i 888 , que era o que se achava em vigor ao findar o Imperio e continuou em vigor na Republica, até se organisarem os Estados, a taxa sobre dividendos não obedecia rigorosamente á definição do imposto de industrias e profissões, visto como este, conforme o artigo I.' do regulamento annexo ao mesmo 
decreto, era devido por todos os que individualmente ou collectivamente (7) exercessem industria ou profissão, arte ou officio, ao passo que, segundo já ficou demonstrado, o accionista paga aquella taxa, não como industrial ou profissional, mas como capitalista, pela. renda liquida auferida da parte que lhe cabe no fundo social; pelo que, se o imposto sobre dividendos naquelle regulamento entra na classe do de industrias e profissões, não é pela identidade e natureza, mas por uma equiparação.»

«Considerando que o proprio decreto n. 9870, de 1888 , distingue o imposto sobre dividendos do de industrias e profissões, tanto que manda, no caso de não haver distribuição de dividendos pelos seus accionistas, paguem as taxas correspondentes ás industrias que exercem (art. 2. ${ }^{\circ}, \S$ I..$\left.^{\circ}\right)$ )

A principal base destes considerandos está, como se vê, em considerar o dividendo como renda do capital e não como proveito industrial; conceito cujo erro patenteámos de modo inilludivel, com a exposição, auctorisada pelos mestres mais insignes, dos prin. cipios da Economia Politica e da Sciencia das Finanças, e com o exemplo do systema de tributação em todos os paizes cultos.

Não será mistér insistir, por consequencia, neste ponto; nos primeiros considerandos, em simples affirmação, déra o accordam o seu erro como verdade scientifica; nestes, allude á demonstração feita naquelles.

(7) Ou em companhia, ou sociedade anonyma, accrescentava o Regulamento de 1888 e accrescenta o de 1898. 
Não podendo, entretanto, vencer a força do principio verdadeiro que ataca, o accordam, elle proprio, reconhece nesse quarto considerando transcripto-que o dividendo é renda liquida auferida da parte que cabe ao accionista no fundo social.

Notada esta preliminar, contrastemos, a outros respeitos, essas duas razões ou bases do julgado.

Em vez do que diz o accordam, o imposto sobre dividendos foi sempre considerado, rigorosamente, um imposto de industrias e profissões no regimen do decreto n. 9.870, de 1888 .

Serve de titulo ao decreto esta inscripção:

"Regulamento para a arrecadação do imposto de industrias e profissöes.»

Ora, a epigraphe da lei e os seus fins são elementos seguros de interpretação; servem para esclarecer disposições obscuras e duvidosas.

(P. Bapjista. - Herm. Furidica, $\S \S 32$ e 33.)

Realmente, não se póde admittir que a lei trate de outro objectivo que o indicado no seu titulo, ou apontado como constituindo seu fim ou justificando sua confecção.

E, se o titulo da lei é um guia seguro para a intelligencia dos textos obscuros, por maioria de razão augmenta a força de expressão daquelles cujo sentido é exposto com clareza, como eram os do regulamento de 1888.

No art. I. dispunha esse regulamento:

" $O$ imposto de industrias e profissões é devido por todos os que, individualmente OU EM COMPANHIA OU SOCIEDADE ANONYMA OU COMMERCIAL exercerem industria ou profissão, arte ou officio.» 
No seu art. 2. ${ }^{\circ}$ declarando o modo pelo qual esses que, individualmente, ou em companhia ou sociedade anonyma, devem pagar o imposto, estatúe que as taxas serão fixas e proporcionaes; e estabelecendo as bases de umas e de outras, diz nos $\S \S 10^{\circ}$ e $2 .^{\circ}$ do mesmo artigo:

« I..$^{\circ}$ As COMPANHIAS ANONYMAS SÃO SUJEITAS A0 IMPOSTO DE I $1 / 2 \%$ SOBRE OS DIVIDENDOS DISTRIBUIDOS AOS ACCIONISTAS;

$\S 2 .^{\circ}$ AS QUE NÃO DISTRIBUIREM DIVIDENDO FICAM SUJEITAS ÁS TAXAS CORRESPONDENTES ÁS INDUSTRLAS QUE EXERCERENI; ; disposição esta ultima reproduzida da advertencia 2. ${ }^{\mathrm{a}}$ da tabella A. (8)

Ora, da leitura das disposições transcriptas resulta:

a) que a lei considerava os accionistas das companhias anonymas industriaes como exercendo industria;

b) que o imposto de industrias e profissões lhes seria cobrado sob a fórma de uma porcentagem sobre os dividendos.

E, se o imposto sobre os dividendos era e é, como quer o accordam, um imposto distincto, sobre a renda do capital, onde a razão pela qual o pagamento do imposto sobre dividendos isentava as companhias do pagamento das taxas correspondentes ás industrias que exercessem?

Se os impostos eram differentes, porque havia de um excluir o outro?

O reg. 9.870 , de 1888 , não fez, portanto, equiparação de um imposto, a outro: cogitou sempre do mesmo imposto, cobrado apenas por modos differentes.

(8) Taes disposiç̃oes são reproduzidas no reg. n. 2.792, de II de Janeiro de 1898 "PARA A ARRECADAÇÃO DO IMPOSTO DE INDUSTRIAS E PROFISSÕES", artigo I..$^{\circ}$ e no reg. n. I.55\%, de 22 de Julho de 1897 , PARA A ARRECADAÇÃO DE IMPOSTO DE DIVIDENDOS. Art. $40^{\circ}$. 
Como é sabido, esse imposto não era cobrado pela fórma percentual sobre as rendas, ás industrias, exercidas individual ou collectivamente, em associaçães de caracter differente, apenas por causa das difficuldades, quasi invenciveis, em precisar-lhes, com segurança, taes rendas. (9)

Nem se diga que esse criterio foi abandonado no systema das leis fiscaes da União.

Ao contrario disso, tem sido mantido com rigor.

Assim é que as disposições transcriptas do regulamento de 1888 foram reproduzidas pelo regulamento n. 2.792, de II de Janeiro de I898-expedido "PARA A ARRECADAÇÃO DO IMPOSTO DE INDUSTRTAS E PROFISSÕES》-nO art. I. $.^{\circ}, \S$ I. ${ }^{\circ}$, e pelo regulamento n. 2.559 , de 22 de Julho de I 897 , regulador da ARRECADAç̃̃o DO IMPOSTO SOBRE DIVIDENDOS, no art. $44^{\circ}$.

UM E OUTRO ISENTAM DAS TAXAS COMmUNS DO IMPOSTO DE INDUSTRIAS E PROFISSÕES, CONSIGNADAS NAS RESPECTIVAS TABELLAS, AS COMPANHIAS QUE PAGAREM A PERCENTUAL SOBRE OS DIVIDENDOS DISTRIBUIDOS.

Onde a razão de taes dispositivos, senão na identidade do imposto?

Por que outra maneira mais expressiva poderiam ter as nossas leis reconhecido que a fonte tributada é a mesma?

(9) A commissão nomeada pelo Snr. Lafayette em I883, para rever e classificar as rendas geraes, provinciaes e municipaes, e "cujo estudo honra os seus autores», na phrase do Snr. Ruy Barbosa, (Relat. da Fazenda ao Chefe do Gov. Prov. em I89I, pag. 216) ao apresentar o seu projecto sobre o imposto da renda, fornece-nos, ainda, um testemunho de que o imposto sobre dividendos das companhias foi sempre considerado, entre nós, como de industrias e profissões, quando diz: E' creado no Imperio o imposto geral sobre a renda, fundado nas seguintes bases:

$30^{\circ}$ Proventos de lucros industriaes etc., acções de companhias (DISPENSADAS ESTAS DO PAGAMENTO DE $1 \frac{1}{2} \%$ DO IMPOSTO DE INDUSTRIAS).

Ora esse $\mathrm{I} 1 / 2 \%$ era justamente $\mathrm{O}$ imposto sobre dividendos. 
Onde uma demonstração mais frisante de que o accionista paga, como industrial, a porcentagem sobre dividendos?

$\mathrm{E}$ bem andaram esses regulamentos.

Nada mais fizeram do que consultar a indole do imposto e a lição de todos os economistas, que incluem os impostos sobre dividendos entre os impostos industriaes. (10)

Vejamos os outros fundamentos.

Para justificar a adjudicação que fez á União de uma attribuição peculiar aos Estados, em materia de impostos, invocou ainda o Tribunal um accórdam anterior:

"Considerando que este Tribunal já reconheceu e decidiu que o imposto sobre dividendos é diverso do de industrias $e$ profissões, como se vê do accórdam n. 165 , de 14 de Agosto de I896».

Não traz esta decisão reforço algum á que vimos impugnando.

Não poderia ella, por varios motivos, servir de amparo ao julgado.

Antes de tudo, é uma decisão isolada e tomada por simples maioria de votos.

A Jurisprudencia não póde ser trazida como elemento de interpretação, ou como fundamento de julgados, senão "quando fundada em uso regularmente

(Io) Vide Leroy-Beaulieu-Science des Finances, vol. $1 .^{\circ}$, cap. $80^{\circ}$; Graziani, Inst. de Scienza delle Finanze, pags. 488; Amaro Cavalcante, Elementos de Finanças, pags. 243 e 244 ; Viveiros de Castro. Tratado dos impostos, pags. 174 e seguintes. 
constituido», «distinguindo-se por uma série de arestos, ou de actos de magistratura sempre constantes $e$ invariaveis por longo espaço de tempo», segundo a lição, sempre auctorisada, de Paula Baptista (op. cit., $\$ \S 49$ e 50), e o consenso dos juristas.

Esse Egregio Tribunal, elle mesmo, tem dado provas de quão fragil é, ás vezes, um julgado, ainda quando proferido sobre assumpto de alta monta.

Resolvendo, por exemplo, sobre competencia jurisdiccional, entre a Justiça Federal e a dos Estados, para conhecimento e decisão de questões relativas a marcas de fabrica, não trepidou elle em abandonar, sabiamente, o voto com que, em varios julgados, se manifestára pela competencia federal, em apoio do preceito flagrantemente inconstitucional da famosa lei n. $22 \mathrm{I}$, de I 894, atamancada no seu contexto e indifferente pela Constituição, como outras tantas votadas nos ultimos tempos.

Não era de invocar-se, porém, o accórdam de I I de Agosto de i 896, por outros motivos ainda.

Tratava-se, na hypothese, de uma companhia fabricante de tecidos, estabelecida no Districto Federal, que, firmada no regulamento de $\mathrm{i} 888$, dizia-se isenta de pagar o imposto sobre dividendos, por isso que estava, por aquelle regulamento, (art. $5^{\circ}$ ) isenta do de industrias e profissões.

Não se discutia a questão de saber se o imposto sobre dividendos de companhias industriaes com séde nos Estados incide na competencia d'estes ou da União.

Poder-se-ia ter dado uma interpretação restrictiva áquella isenção, sem preoccupação com a grave questão da competencia dos Estados para o imposto sobre dividendos; o que não estava em causa, até porque 
a companhia tinha sua séde no districto federal e nelle exercia sua industria.

A decisão foi, aliás, mesmo nesses limites, e fóra de taes preoccupações, inilludivelmente desacertada.

Se, pelo regulamento em vigor na occasião, que era o de I 888, o imposto de industrias e profissões que pagavam as companhias era, segundo a regra geral, o de uma porcentagem sobre os dividendos e, só por excepção o das tabellas communs, claro é que a isenção devia aproveitar á companhia querellante, sob pena de ser essa isenção uma inutilidade.

$\mathrm{E}$, tanto na isenção do imposto de industrias. e profissões se comprehendia o de dividendos, que, ao destacar-se este para um regulamento á parte-o de 22 de Julho de 1897 -foram mantidas as isenções contidas naquelle, de I888, ao qual se faz remissão expressa: isto no art. $3 .^{\circ}$, assim redigido:

«São isentas do imposto de dividendos as companhias de fabricas de tecer e far algodão, de ferro e de machinas, estaleiros, linhas telegraphicas e telephonicas (regulamento n. 9.870 , de 22 de Fevereiro de 1888 , art. $5^{\circ}$, ns. 9 a 12 )».

São, justamente, as isenções do imposto de industrias e profissões, consignadas no regulamento de I 888, que o Governo transplantou para o de 1897 sobre dividendos.

E' o proprio Governo da Republica quem diz, por consequencia, no reg. de I897, que o reg. I 888, ao qual faz remissão expressa, nas isenções do imposto de industrias e profissões, comprehendia o de dividendos, e conseguintemente, que este imposto é um imposto de industrias e profissões; que os dous são uma e a mesma cousa. 
Em mais uma base, muito fragil, arrimou-se, portanto, o veridictum do Supremo Tribunal, que não melhorou as suas conclusões com as ultimas premissas.

\section{V}

Os dous ultimos fundamentos do accórdam, repetindo os conceitos anteriores, concluem:

"Considerando, nestes termos, que o imposto sobre divideridos de acções, distincto, por sua natureza, (!) do de industrias e profissões, não está de fórma alguma comprehendido no art. $90^{\circ}$ n. 4 , da Constituição Federal, que não póde, como se pretende, ter adoptado a classificação anterior, que arbitrariamente, equiparou um imposto ao outro, pelo que as recentes leis orçamentarias da Republica, incluindo na receita geral da União o imposto sobre dividendos em todo o territorio nacional, não violaram aquelle dispositivo constitucional, e, portanto, não podem deixar de ser executadas ;

«Considerando que, não incorrendo o imposto controvertido na censura do art. Io da Constituição, enquadra-se perfeitamente na generalidade do art. I 2 da mesma Constituição, que faculta á União e aos Estados crear cumulativamente outras fontes de receita, além das discriminadas nos artigos anteriores, e com as limitações nelles estabelecidas, julgam, etc.» 
Temos demonstrado que, por sua indole, o imposto sobre dividendos recáe directamente sobre os lucros das industrias; que assim foi considerado pelo regulamento de 1888 e ainda o é pelos regulamentos de 22 de Julho de 1897 e de I I de Janeiro de I 898 , sendo que o de 1897 dispõe, no seu art. 2.. :

«O imposto (sobre dividendos) é devido na razão de $21 / 2 \%$ sobre os dividendos dos lucros auferidos pelos ditos BanCOS, COMPANHIAS E SOCIEDADES ANONYMAS», e (art. $5^{\circ}$ ) "comprehende as quantias pagas a titulo de bonificação, ou outro por que se distribuam os lucros.»

Ora, os lucros, reaes ou presumidos, das diversas industrias são justamente o objecto sobre que incide o imposto de industrias e profissões.

«Tratando d'este imposto, diz LeRoY Beadleu, no trecho já transcripto: Il a pour base, en effet la moyenne supposée des bénéfices que chaque catégorie de négociants peut raisonnablement obtenir dans conditions determinées d'exploitation.

Depuis I 79 I jusqu'à l'heure actuelle, il y a eu un effort constant pour rendre l'impôt des patentes de plus en plus proportionel aux bénéfices du contribuable.»

"L'imposta industriale, diz Grazianr (op. cit., pag. 362), colpisce il prodotto netto delle industrie, nel senso più largo de la parola, cioè il profitto delle im. prese produttive.» 
FRED. FLORA, no seu excellente Manuale della Scienza delle Finanze, ensina, por sua vez, tratando do obiecto do imposto de industrias :

«L'imposta sul prodotto dell'industria colpisce $i$ profitti del intraprenditore». (pag. 325).

No seu preciosissimo Trattato completo di Diritto Amministrativo Italiano, TRATANDO DO IMPOSTO INDUSTRIAL, diz o notavel, professor V. Orlando, referindo-se ás objecções que soffre esse imposto:

«Tuttavia, se la tenuità dei guadagni è una ragione amınissible per stabilire un minimo di esenzione, tutti gli altri argomenti, che si adducano, non hanno alcun valore dinanzi al principio generale della imposta, commisuratto al reddito, qualunque sia la fonte immediata da cui deriva.» (Vol. 9. ${ }^{\circ}$, pag. 263).

«LE INDUSTRIE E LE PROFESSIONI BONO TASSATE SECONDO UN REDDITO HYPOTHETICO 0 approssimativo.». (Vol. cit., pag. 272).

O Sr. Viveiros De CásTro, no seu Tratado dos impostos, citando Amaro Cavalcanti, diz, á pag̣. I 74 , QUE 0 IMPOSTO DE INDUSTRIAS E PROFISSÕES GRAVA OS RENDIMENTOS DE UMAS E OUTRAS.

E sobre isto não ha controversia, nem duvida para ninguem.

Ora, se este imposto recáe sobre os lucros, proveitos ou rendimentos das industrias; e se o imposto sobre os dividendos incide sobre os hicros anferidos pclas companhias industriaes, segundo a lettra do proprio decreto que o rege (2.559, de 22 de Julho de 1897 , art. $\left.2^{\circ}\right)$, como admittir a proposição do accór- 
dam-de que são elles «impostos distinctos por sua natureza?"

Como admittir que os de dividendos gravam outras fontes que não as industrias, attribuidas no art. $9 .^{\circ}$, n. 4, da Constituição á competencia exclusiva dos Estados, nestes termos: " $E$ " da competencia exclusiva dos Estados decretar impostos SOBRE industrias e profissões?»

Ainda quando, contra toda nossa indestructivel demonstração, a mudança de nome pudesse separar, na technica das nossas leis fiscaes, o imposto sobre dividendos do imposto de industrias e profissões, a identidade do objecto em que incidem não permittiria attribuir aquelle á auctoridade da União, deante da amplitude do clarissimo texto constitucional: «competencia exclusiva para DECRETAR IMPOSTOS (sem nenhuma limitação) SOBRE industrias e profissões.»

E assim sempre entendeu o proprio Congresso Constituinte, e ainda o que se lhe seguiu: até que um terceiro, animado pelos abusos com que tinha sido já ferida em outros pontos a Constituição, unsou violal-a tambem neste, o que aliás não tem conseguido, sem incorrer nas mais descobertas inconsequencias.

Ao lado das auctoridades scientificas e da lição dos povos cultos, collocámos do nosso lado a propria Fazenda Federal, o proprio governo da Republica, no seu regulamento de I897; não só quando estatúe que o imposto sobre dividendos recáe sobre os lucros das companhias industriaes, isto é, sobre uma fonte de renda outorgada exclusivamente aos Estados, como quando isenta desse imposto todas as companhiäs industriaes que, no regulamento de 1888 , cujos termos 
reproduz e aos quaes faz remissão, estavam isentas do de industrias e profissões.

Pois bem, invoquemos agora o testemunho do Poder Legislativo.

A lei n. 25 , de 30 de Dezembro de I89 I, estabelecer ao imposto de $\mathrm{I} 1 / 2 \%$ sobre dividendos das sociedades anonymas, de um modo geral.

Quando se teve de dar execução a esta lei, entendeu o governo que o imposto se referia, apenas, ás sociedades anonymas com séde no Districto Federal e n'este sentido expediu circular.

Nos dous annos seguintes, confirmou o mesmo Congresso, expressamente, a intelligencia dada pelo governo á lei de I89I, isto 'nas leis n. I 26, de 2 I de Novembro de I892, e n. I 9 I, de 30 de Setembro de I 893, PELAS QUAES ESSE IMPOSTO RECAHIU EXClUSIVAMENTE SOBRE AS COMPANHIAS COM SÉDE NO DISTRICTO FEDERAL.

No mesmo sentido manifestou-se o Congresso seguinte em tres leis orçamentarias successivas: as leis -n. 265 , de 24 de Dezembro de 189 , art. $1 .^{\circ}, n$. 1 ז; n. 359, de 30 de Dezembro de 1895 , art. $1 . \circ$, n. 30 , e n. I 28 , de $1 .^{\circ}$ de Dezembro de I896, art..$^{\circ}$, n. 39 .

Ora, só ao reconhecimento de que não competia á União estender esse imposto ás companhias com séde nos Estados, por se tratar de imposto sobre industrias e profissōes, se póde attribuir a restricção delle ás companhias com séde no Districto Federal.

De outro modo teria o Congresso attendido, não só ao disposto no art. $72, \S$ ז.', como ainda, especialmente, ao art. $7 .^{\circ}, \S 2 .^{\circ}$, da Constituição Federal, onde se determina que oS IMPOSTOS DECRETados PELA UNIÃo DEVERT̃O SER UNIFORMES PARA TODO 0 TERRITORIO DO PAIZ. 
Entre as duas soluções, a de ter o Congresso violado abertamente o preceito terminante do art. $70^{\circ}$, $\S 20^{\circ}$ e a de ter respeitado religiosamente a do art. $9 .^{\circ}$, n. 4 , haverá quem prefira a primeira?

Ainda mais: temos, do proprio Congresso Federal, uma manifestação recente de que a União não póde, sem violar o art. $90^{\circ}$ da Constituição, crear impostos de renda sobre as fontes de renda attribuidas por esta exclusivamente aos Estados.

A commissão respectiva da Camara dos deputados consignára no art. io do projecto de orçamento para o anno de 1898 o imposto de renda, recahindo sobre os immoveis e sobre os lucros industriaes.

ESTE IMPOSTO FOI, PORÉM, REJeITADO, EM VIRTUDE DE uma emenda dos Srs. depttados Paula Ramos a Alerkedo Pinto, QUe pediram a SUPRessão do Át. io, por SER iNCONSTITUCTONAL.

E foi rejeitado, apesar dos esforços da commissão, que affirmava ser elle baseado no art. I 2 da Constituição Federal. (Sessão de I. ${ }^{\circ}$ de Dezembro de I897). (I I)

Cumpre notar que o art. io do projecto da commissão de orçamento, rejeitado pela Camara como inconstitucional, por gravar materias tributaveis exclusivamente pelos Estados, estabelecia no seu $\S$ ro: "Cobradas que sejam as taxas a que se refere este artigo, cessará a do n. 40 do art. $I^{\circ} .^{\circ}$ sobre dividendos de companhias e sociedades anonymas.»

Se a Camara reconheceu que o imposto sobre dividendos, consignado no art. $1 \mathrm{O}$, n. 2, era o mesmo do art..$_{\circ}^{\circ}$, n. 40 , e se rejeitou aquelle, por inconstitucional, como póderia manter este?

$$
*^{*} *
$$

(I I) O discurso do Sr. Alfredo Pinto, sustentando essa emenda, foi pronunciado na sessão de 13 de Novembro de 1897 e o do Sr. Paula Ramos na de 30 do mesmo mez. 
A referencia a esta conducta do Congresso lembra-nos ainda uma outra razão apresentada em favor da constitucionalidade do imposto.

A allegação feita, por alguns, de ser o imposto sobre dividendos um imposto sobre a renda, não melhoraria a sorte da União, nem salvaria do vicio de inconstitucionalidade o imposto que ella tem cobrado ás companhias anonymas.

Admittido que, com a mudança de nome, com a designação de-imposto de renda, se tornasse ir discutivel a competencia da União, perguntamos:

Por que razão deverão as sociedades anonymas pagar impostos sobre suas rendas, quando não o pagam os capitalistas que auferem renda dos seus capitaes dados a juros, nem as sociedades em nome collectivo, nem as commanditarias e quaesquer outras, nem, ainda, as rendas auferidas de outras fontes?

Este fundamento, de inconstitucionalidade do imposto, resultante da maneira desigual com que são taxadas as companhias, está posto em relevo, aliás involuntariamente, pelo Sr. Anisio de Abreu, o esclare cido relator da Commissão do Orçamento da Camara dos Deputados, em varios pontos de seu parecer sobre o projecto da receita para o anno vindouro.

Depcis de exaltar as vantagens do imposto sobre a renda, que a Commissão rejeitára, diz o illustre deputado, que a Commissão, "pensando d'essa fórma, julgou de seu dever acceitar a emenda que manda cobrar o imposto sobre dividendos em todos os Estados e pensa que o imposto sobre a renda deve ir tendo grande extensão.» (Pag. 30).

Aqui está a Commissão, que rejeitou o imposto geral sobre a renda, mandando cobral-o sómente á que é representada pelos dividendos das companhias. 
Mais adiante, defendendo sua proposta de tributação da renda das apolices, continúa o illustrado parlamentar:

"E' inconcebivel que se taxe o ca. pital activo, o capital circulante, que auxilia, QUE MOVIMENTA, QUE IMPULSIONA, QUE DESENVOLVE E QUE FECUNDA A INDUSTRIA, O COMMERCIO, A LAVOURA, e qu se poupe o capital inerte, o capital parasita, ocioso, o mais seguro e o melhor garantido.»

«Sijeitando ao mesmo imposto, nivelando DIANTE DO PRINCTPIO GERAL DA IGUALDADE DE TAXAÇÃO 0 possuidor de titulos da divida publica e o possuidor de ações de empregos industriaes e de commercio, o legislador nada mais faz do que realisar o pensamento de Pitt, quando, em nome dos interesses nacionaes, dos interesses superiores e permanentes da justiça, da egualdade e do bem publico, cassou o privilegio de que gozavam os consolidados inglezes.»

Em diversos outros trechos (pags. 38 e 39) salienta que a isenção da renda das apolices importa em uma violaşão do preceito constitucional da egualdade perante a lei, "que é o principio dominante em todas as naç̃ös.»

No ultimo d'esses trechos, repetindo conceito de Vraye, assim se exprime o autorisado relator da Receita:

«Não é menos certo, não só no «sentido equitativo, como legal e CON«STITUCIONAL que a renda prove«niente de titulos do Estado, não póde «ficar isenta de um imposto que affecte «indistinctarnente, na mesma proporção, 
«todas as rendas moveis; INVOCAR EM «SEU FAVOR UMA ISENÇÃO, SERIA BARATEAR «OS. PRINCIPIOS QUE, INVARIAVELMENTE, PRO"CLAMAMI A EGUALDADE PERANTE 0 IMPOSTO.»

$\mathrm{Si}$ a isenção da renda das apolices fere assim, tão directamente, o principio de igualdade perante a lei, consignado no art. $72 \S 20^{\circ}$ da Constituição, muito mais accentuada e inilludivel é a violação d'esse preceito nas leis orçamentarias que, isentando todas as demais rendas, têm gravado unicamente a das sociedades anonymas.

$$
* *
$$

Mas, que valor terá a defeza da competencia federal para o imposto sobre dividendos, fundada em ser elle um imposto sobre a renda?

Nenhuma absolutamente.

Em primeiro logar, porque, sendo o imposto, em geral, uma parte das rendas individuaes retirada para as despezas do Estado, não haveria imposto que a União, com esse fundamento, não pudesse lançar sobre as materias attribuidas exclusivamente á competencia dos Estados.

Em segundo logar, porque os impostos de industrias e profissões são impostos sobre a renda como já vimos; de modo que estes poderiam tambem ser lançados pela União, se prevalecesse aquella razão.

Entre nós, como nos demais paizes, o imposto de industrias e profissões sempre foi considerado um imposto sobre a renda.

Em I 879, tendo o Sr. Affonso Celso ouvido a opinião de diversos competentes sobre o que se poderia fazer para o estabelecimento do imposto de renda, 
recebeo, entre outros pareceres, o do Sr. Honorio Ribeiro que dizia:

\author{
- «O nosso systema tributario já \\ conta effectivamente alguns impostos \\ sobre a renda TAES COMO 0 DE INDUSTRIAS \\ E PROFISSÕOS, O PREDIAL E OUTROS.»
}

No mesmo anno a commissão de orçamento da Camara dos Deputados dizia, em relação ao imposto de renda:

«Actualmente uma classe de contribuintes, além «do que paga de taxas indirectas, por estar confun«dida com a massa da população, é tributada com o «imposto sobre a rendã: TAL É A QUE PAGA O IMPOSTO «PREDIAL E 0 DE INDUSTRIAS E PROFISSÕES»; e propunha o seguinte:

IX Cobrar-se-hão $5 \%$ sobre a
renda dos contribuintes que nãa pagarem
o imposto de subsidio, de vencimento e de
industrias e profissöes. (I 2 ).

Ora, se o imposto sobre dividendos é, como já demonstrámos, um imposto de industrias e profissões e foi sempre assim considerado no nosso regimen fiscal; e se o imposto de industrias e profissões, foi sempre considerado entre nós, de accordo com o sentir universal dos economistas, um imposto sobre a renda, claro é que não prevalece a allegação de pèrtencer á competencia da União o imposto sobre dividendos, por ser um imposto sobre a renda.

Em terceiro logar, usando a Constituição Federal, no art. $9 .^{\circ}, \S 4 .^{\circ}$, de uma expressão amplissima,

(12) Uma outra confirmação de que o imposto de industrias é por sua natureza um imposto sobre a renda, está n'estas palavras de Graziani, op. cit. pag. 469: "Il tipo profondamente opposto al francese in materia d'im. posto industriale è l'inglese, secondo cui questo tributo costituisce parte del tributo generale sul reddito. 
em que attribúe aos Estados, exclusivamente, todos os impostos que recaiam SOBRE industrias e profissões, claro é que, ainda que tenha o nome de imposto de renda ou outro qualquer, nenhum poderá a União lançar que affecte taes materias.

A preoccupação maior de todos os paizes como de todos os financistas, ao cogitarem do imposte sobre a renda, tem sido sempre a da sua superposição a outros impostos directos; superposição confessada por todos e inilludivel.

A este respeito pondera Leroy Beadlieu (op. cit., pag. 443):

"L'impôt génèral sur le revenu se superpose d'ordinaire aux impôts directs qui frappent les revenus morcelés, tels que l'impôt foncier, l'impôt mobilier, l'impôt des patentes; il en resulte qu'on l'accuse souvent DE FAIRE DOUBLE EMPLOI avec les autìes impôts directs.»

A' pag. 395, havia elle dito, de modo mais cathegorico:

"Dans beausoup de contrées les taxes. sur les bénéfices de l'industrie, du commerce et des professions libérales, sont confondues dans l'impôt général sur le revenu et en forment une catégorie, une cedule, comme on dit en Angleterre.»

"Mais, dans beaucoup de pays aussi, à coté de la partie de l'impôt sur le revenu, qui frappe les profits du commerce et de l'industrie, il $y$ a une autre taxe spéciale, FAISANT DOUBLE EMPLOI ET GREVANT, SOUS DIVERS NOMS, L'EXERCICE DE CERTALNES PROFESSTONS ET DE CERTAINES ENTREPRISES». 
No mesmo sentido Flora (op. cit., pag. 343), Graziant (op. cit., pag. 488) e todos os economistas.

Ora, se a coexistencia do imposto sobre a renda das industrias com outros impostos que as attinjam, importa em uma duplicata de impostos, em uma taxação dupla sobre a mesma materia tributavel ou sobre a mesma fonte de renda, indiscutivel se torna ser inadmissivel que a União tribute com o chamado imposto de renda, materias tributaveis attribuidas á competencia exclusiva dos Estados.

Se, nos paizes, em que não existe a discriminação de rendas exigida entre nós pelo regimen federativo, se registra essa preoccupação $\mathrm{com}$ a duplicata que acarreta o. imposto sobre a renda, no nosso essa duplicata torna-se um obstaculo invencivel, deante do art. 9. da Constituição.

Se o facto, de ser o imposto sobre dividendos um imposto sobre a renda, justificasse a intromissão da União, não haveria imposto em que ella pudesse ser repellida.

De que valeria o exclusivismo das fontes attribuidas aos Estados pelo art. 9. ${ }^{\circ}$ da Constituição, principalmente as dos ns. 2 e 4 ?

Que infinidade de taxas novas não imaginaria a União para competir com elles?

Onde a vantagem da discriminação das rendas, desde que a acção cumulativa, em vez de procurar outras FONTES, segundo o preceito do art. I 2, se exerceria mesmo sobre as do art. 9. ${ }^{\circ}$, que elle manda respeitar!

\section{VI}

Demonstrado de modo irrespondivel, como parece ter ficado, que o imposto sobre dividendos foi sempre 
considerado pelas nossas leis fiscaes como de industrias e profissões; e, ainda, que esse imposto attinge directamente os proveitos industriaes, que attinge directamente as industrias, tão directamente quanto os que, sem discrepancia de ninguem, se chamarem de industrias e profissões;-que, por consequencia, a materia tributavel, ou a fonte de receita por elles procurada é a mesma; vejamos se essa fonte-industrias - está sujeita a uma taxação cumulativa da União e dos Estados, estudando o elemento historico da Constituição.

Seria de todo inutil esta indagação, se não se tivesse revelado tão inexpressiva e tão sem valia, ao espirito esclarecido dos eminentes juizes, a inexcedivel clareza com que o art. $9 .^{\circ}, \S 4 .^{\circ}$, da Constituição, em preceito da mais lata comprehensão, estatúe positivamente:

«E' da competencia EXcLustya dos Estados DECRETAR IMPOSTOS SOBRE industrias e profissões.»

Verificada, porém, a divergencia entre o nosso e o modo de vêr de tão conspicuos juristas, procuremos, nos annaes da Constituinte e no testemunho dos que nella foram factor de mais vulto, uma confirmação categorica de que, na lettra inequivoca do art. 9.., se reproduziu fielmente o pensamento dos auctores da Constituição.

No seu parecer sobre a materia, lavrado em 5 de Dezembro de 1893 e constante desses annaes, diznos a commissão dos Vinte e Um:

«Foram objecto de longa discussão os artigos da Constituição relativos á discriminação das rendas provenientes de impostos.»

«Ao systema ahi adoptado, que consiste em dar á Uniăo e aos Estados competencia ExcLUsiva PARA 
TRIBUTAREM DETERMINADAS FONTES DE RECEITA E CUMULATIVA PARA TRIBUTAREM OUTRAS, se contrapoz o da completa e absoluta discriminação das MATERIAS TRIBUTAVEIS por parte da União, considerando-se todas as mais da competencia dos Estados.»

«A maioria da Commissão, porém, attendendo a que, dada a eventualidade de desequilibric no orçamento federal, teria a União de recorrer a quotas repartidas entre os Estados, o que a pôria na dependencia destes e poderia crear-lhe serios embaraços, em condições excepcionaes, como em caso de guerra, ou de calamidade publica, RESOLVEU MANTER AS DISPOSIÇ̃̃ES DA constinUiçãa», isto é, as que dão aos Estados competencia exclusiva para tributarem certas materias e cumutativa para tributarem O0TRAS.»

Deste trecho resultam duas conclusões:

I. $^{a}$ que a discriminação constitucional das rendas se fez por materias tributaveis;

2. ${ }^{a} \quad$ que as materias sobre as quaes se estabeleceu a competetencia cumulativa da União e dos Estados são outras que não as enumeradas no art. 9..

Referindo-se aos impostos attribuidos no art. 9. aos Estados, disse o eminente Snr. Ruy Barbosa, que foi um dos auctores do projecto da Constituição: "Nessas FONTES DE RENDA que o projecto thes reserva privativamente, DE QUE O PROJECTO EXCLUE ABSOLUTAMENTE A UNIÃ̃. .., sobram-lhes meios para a vida sem estreiteza no seio da Federação» (sessão do Congresso, em I 6 de Novembro de I 890).

Esclarecendo ainda mais o pensamento da Commissão e o da Constituinte, o Snr. Leopoldo Bulhões, actual ministro da Fazenda, que foi tambem um dos membros daquella e dos que, pela sua competencia, mais influencia exerceram nas suas deliberações, diz- 
nos em seu discurso, pronunciado a 5 de Outubro de 1900, no Senado federal:

«A experiencia do acto addicional havia condemnado os impostos cuimulativos: a tradição nacional e a indole do novo regimen repelliam o systema dos impostos addicionaes para o custeio dos serviços estadoaes: a DIVISÃ̃ DAS FONTES SE IMPOZ, então ao Governo Provisorio e á Constituinte.»

A exactidão destes testemunhos está por sua vez posta em evidencia no texto do art. I 2 da propria Constituição.

"Além das fontes de receita discriminadas nos arts. $70^{\circ}$ e $90^{\circ}$, preceitúa elle, é licito á União como aos Estados, cumulativamente ou não, crear outras quaesquer, NÃO CONTRAVIINDO O DISPOSTO NOS ARTIGOS 7.0, 9.. Е I I. \%, N. I.»

Ora, se o art. $7 .^{\circ}$ tem por unico objecto a enumeração das materias tributavieis exclusivamente pela União, e o art. 9. ${ }^{\circ}$, a das tributaveis exclusivamente pelos Estados, é logico que só haverá contravenção do disposto em taes artigos, se a União gravar corn impostos as materias attribuidas exclusivamente aos Estados, ou vice-versa.

E' irrecusavel, portanto, a conclusão: se a União tributar, por qualquer modo, as industrias, contravém ao art. 9. ${ }^{\circ}$ n. 4, da Constituição.

$$
\text { ** } *
$$

Egualmente violado com a doutrina do Supremo Tribunal e ainda o art. io da Constituição, que prohibe à União tributar bens e rendas ou serviços a cargo dos Estados. 
Com a taxação dos dividendos distribuidos pelas companhias que exercem industrias nos Estados, a União não tributa directamente renda dos Estados; mas o faz indirectamente, e de modo tão grave e, talvez, mais sensivel, do que se o fizesse directamente, porque lhes enfraquece, em escala não medida, uma das mais importantes fontes de receita.

E' effeito seguro dos impostos que affectam as industrias o de diminuir-lhes, ou entorpecer-lhes o desenvolvimento; effeito que se accentúa com a aggrava. ção das taxas.

São da auctoridade incontestada de Stuart Mill estes conceitos :

«Le véritable effet d'un impôt sur les profits est de faire qu'à un moment donné le pays ait un capital moindre, UNE PRODUCTION TOTALE MOINDRE, ET ARRIVE PLUTÔT À L'ÉTAT STATIONAIRE AVEC UNE SOMME MOINDRE DE RICHESSE NATIONALE.»

«Cette Charge tend À fatre ÉMigrer LES CAPITAUX, À PROVOQUER LES SPÉCULATIONS IMPRUDENTES, EN REDUISANT LES BÉNÉFICES REGULIERS, À DECOURAGER L'ESPRIT D'ACCUMULATION ET À FAIRE ARRIVER PLUTÔT LA SOCIÉTÉ À L'ÉTAT STÁTIONAIRE.» (Op. cit. 2. vol., pags. 4 I 9-430).

No mesmo sentido manifesta-se Leroy Beaulieu. (Op. cit. v. 1..$^{\circ}$ pags. 422 e 423 ) salientando o effeito deprimente que, sobre as industrias, produzem os impostos sobre os dividendos das companhias, os quaes produzem não só uma desvalorisação dos respectivos capitaes, como ainda a emigração de capitaes, que, de outro modo, nellas se empregariam. Resulta disto, 
indubitavelmente, que o imposto sobre dividendos das companhias com séde nos Estados, diminuindo uma fonte de rendas destes, grava inilludivelmente essas rendas.

Se os Estados, não se importando com o imposto da União, taxarem cumulativamente os dividendos, todas essas consequencias, apontadas pelos economistas e de facil intuição, avolumar-se-ão desmedidamente.

Se se abstiverem deante da tributação da União, softrem nos seus orçamentos muito mais do que se ella lhes cobrasse uma porcentagem da renda arrecadada.

- Imagine-se, agóra, a que consequencias não levaria a doutrina do Supremo Tribunal, se a União, muito logicamente, : usasse do mesmo processo em relação ás demais fontes de renda consignadas no art. 9.\%, como já pretendeu fazer mais de uma vez!

Desappareceriam todas as materias attribuidas á competencia exclusiva dos Estados e seriam, em vez de simplesmente tributadas, usurpadas as rendas destes; desappareceria inteiramente a discriminação das rendas que tanto preoccupou os Constituintes.

A prevalecer a doutrina do Supremo Tribunal, o regimen, instituido como regra pela Constituição, seria o de uma competencia cumulativa em relação a todas as fontes de renda, quando o artigo I 2 só a admitte como excepção e referindo-se a materias não comprehendidas nos arts. $7 .^{\circ}$ e $9 .^{\circ}$

$$
\text { ** }
$$

Em summa, não poderão os defensores do imposto sahir d'este dilemma: ou o imposto sobre dividendos é um imposto de industrias e profissões e é 
inconstitucional a sua creação pela União, deante do art. 9. ${ }^{\circ}$ n. 4 da Constituição.

Ou esse imposto é um imposto de renda, e é inconstitucional, tal como tem sido creado, gravando sómente os dividendos das companhias, por isso que fere 0 art. $72 \S 20^{\circ}$ da mesma Constituição.

Do mesmo modo não poderão fugir d'este outro:

Ou a Constituição, no art. $9 .^{\circ} \S 44^{\circ}$, transferio aos Estados os impostos de industrias e profissões taes como existiam no regimen das nossas leis fiscaes e, então, n'elles se comprehende o de dividendos;

ou fez a Constituição uma discriminação inteiramente nova, por fontes de rendas ou materias tributaveis, e então compete elle ainda aos Estados, porque grava uma dessas materias - as industrias - attribuidas á competencia tributaria, exclusiva, dos Estados.

$$
*^{*} *
$$

Refuta, assim, todos os argumentos produzidos em favor da competencia da União, é preciso convir que só poderia valer á respeitavel decisão, um argumento ad terrovem: o de que seria a União obrigada á restituição de avultada somma, se proclamada a inconstitucionalidade do imposto, por ella creado e arrecadado.

Essa restituição seria hoje de tres mil contos, mais ou menos, attendendo-se a que a ampliação do imposto aos Estados data de 1898 e que a média annual da arrecadação do imposto nos Estados tem sido de seiscentos contos.

Mais tarde seria muito maior o sacrificio.

Mas não é possivel que ao Guarda Supremo da Constituição impressionem argumentos desta catadura. 
Elle não se quererá transformar, de mantenedor dos principios fundamentaes do regimen em salvaguarda de conveniencias do momento e de injustificaveis subversões desses principios; sob pena de faltar-lhe amanhã, e á União, a força necessaria para cohibir os abusos de uns Estados contra outros e contra propria União; sob pena de se lançar em uma confusão mortifera o regimen federativo, que não póde ser affectado em ponto mais melindroso que o da discriminação das rendas instituida no Pacto Fundamental.

S. Paulo, Outubro de I9o3.

Dr. TKanoel Bedro Willaboim. 


\section{0 imposto sobre dividendos no Congresso}

Querendo, a todo transe, defender a competencia da União para os impostos sobre dividendos, de que temos tratado, a illustre Commissão da Camara dos Deputados, apresentou, a respeito de emenda suppressiva d'esses impostos; um parecer de incongruencia inegualavel. $(*)$

Parece que a logica se afugentou de uma vez do espirito dos nossos legisladores!

Das premissas d'esse parecer, as que não repellem abertamente a conclusão, peccam por se basearem, apenas, em erros anteriores.

Assim, por exemplo, pensa a Commissão que o imposto compete á União, porque o Congresso já o decretou, em diversas outras occasiões.

A este argumento responderemos que tambem o Congresso, nas leis orçamentarias de I89i a I897, decretou o contrario; devendo-se notar que tres d'essas leis foram do proprio Congresso que votára a Constituição.

(*) Esse parecer tem a data de 25 de Novembro proximo passado. 
Mais adeante pondera a Commissão

«A competencia da União para decretal-o é incontestavel em face da Constituição.

«Esta, de facto, adoptando o systema da mais rigorosa discriminaçâo, em partes differentes, em artigos e paragraphos distinctos, separadamente dispoz a materia dos impostos: primeiro, nos arts. $70^{\circ}$ e $90^{\circ}$ delimitou a esphera das competencias tributarias da União e dos Estados, ENUMERANDo especificadamente, nominalmente, DENTRE OS IMPOSTOS EXISTENTES OS ESCLUSIVOS DE UMA E OUTRA; depois, nos arts. Io e I I o que era vedado ao poder de taxação de ambos, e, finalmente, no art. I 2 sem precisar, sem definir, de modo amplo e generico, indistinctamente, as fontes de rendas que aos mesmos é facultado explorar, cumulativamente ou não, sem prejuizo e offensa das exclusivas de cada um, mencionadas nos artigos anteriores.»

A inconsequencia, em que incorre com esta allegação, é palpavel.

$\mathrm{Si}$ a Constituição adoptou «o systema da mais rigorosa discriminação nos arts. $70^{\circ}$ e $90^{\circ}$ enumerando especificadamente, nominalmente, DENTRE OS IMPOSTOS EXISTENTES os exclusivos da União e dos Estados,» é forçoso concluir, contra a Commissão, que o imposto sobre dividendos ficou pertencendo aos Estados, porque EXISTIA, então, como imposto de industrias e profissões no regulamento de $\mathrm{I} 888$.

$\mathrm{E}$ se, além da letra clarissima d'esse regulamento de I 888, fosse preciso invocar mais algum argumento para provar que o imposto sobre dividendos SEMPRE Existro nas nossas leis fiscaes como imposto de industrias e profissões, invocariamos um trecho transcripto pela propria Commissão e da lavra de uma autoridade por ella muito festejada, isto é, da Commissão 


\section{$-181-$}

da Camara dos Deputados que, em I879, propôz o imposto sobre a renda.

Essa Commissão pretendia que se creasse a taxa de $5 \%$ sobre:

«a renda de juros de lettras, de quantias depositadas em bancos, ou emprestadas a particulares, de apolices da divida publica geral, provincial ou municipal, de acções de companhias (DISPENSADAS ESTAS DE I $1 / 2 \%$ DO IMPOSTO DE INDUSTRIAS》.

Ora, esse I $1 / 2 \%$ Do Imposto DE INDUSTRIAS era, justamente, o imposto sobre os dividendos.

Por consequencia, se a Constituição deo aos Estados a competencia exclusiva para os impostos de industrias e profissoes, taes como existiam, deo-lhes, irrecusavelmente essa competencia exclusiva para os impostos sobre dividendos das companhias existentes nos seos territorios.

Cumpre, porém, notar que, como demonstrámos, a Constituição attribuio taes impostos aos Estados, com uma formula muito mais ampla, dizendo:

«Compete exclusivamente aos Estados decretar impostos SOBRE industrias e profissões.» (Art. 9. ${ }^{\circ}$ n. 4). (**)

$$
*^{*} *
$$

(**) Procurando apadrinhar-se com uma autoridade de grande valor, diz, ainda, a Commissão: «Aos Estados ja estava deferida a competencia para tributar, exclusivamente, as industrias e profissoes, quando o primerro Ministro da Fazenda da Republica, no seu relatorio de I89I, julgava constitucional, necessario e imprescindivel que a União, para corrigir as deficiencias $e$ desigualdades do seu systema de tributaçâo, recorresse ao imposto geral sobre a renda, attingindo este todos os rendimentos, sem excepcâo de um só, o juro das apolices inclusive."

Não é exacta esta informação. O relatorio do eminenteSnr. Ruy Barboza foi apresentado ao Chefe do Governo Provisorio nos primeiros dias de 
A este segue-se um outro raciocinio da Commissão, verdadeiramente entontecedor, expresso n'estas palavras:

«Os que se apegam ao argumento ou antes á allegação de que se dá assim uma incidencia de taxação, esquecem-se ou simulam ignorar que o caracter typico do imposto sobre a renda é justamente o de ser elle uma taxa complementar de reparação e compensaça $\tilde{o} o$, que, para corresponder a este fim, tem de superpor-se a quaesquer outras taxas de denominações diversas, que porventura já ONEREM A RENDA. Não seja assim, e terá perdido a sua feição peculiar, a sua caracteristica essencial de tributo, que, SEM INDAGAR DA PRECEDENCIA (!) attinge aos lucros ou proventos da propriedade e da riqueza nas suas varias modalidades-movel, immovel, rural ou urbana, só assim sendo o que elle é: «um tributo geral sobre os proventos da propriedade, das profissões, do commercio e dos officios».

Mas, si o imposto sobre a renda é um imposto de «reparaçãa e compensação» dos effeitos dos impostos directos, como admittil-o, lançado pela União, quando os impostos directos o são pelos Estados, de modos diversos, e por taxas desiguaes?

Janeiro de I891. A esse tempo não tinha sido ainda approvada a emenda do deputado Lauro Sodré e de outros, passando para os Estados os impostos de industrias e profissões. Não estava ainda votada a Constituição.

Essa emenda foi apresentada na sessão do Congresso Constituinte, de 16 de Dezembro de I89o, (Annaes do Cong., pag. 215.) quando, de certo já estava confeccionado o relatorio invocado. O que se póde admittir é que o grande mestre tenha lembrado uma providencia para ser consignada na Constituição. 
A reparaşão e a compensaşão não se transformariam, muitas vezes, em aggravação insupportavel?

Não poderia servir o imposto de compensaşão ou de reparaşẫo em uns Estados e de desiquilibrio ou de oppressão ou de depauperamento em outros?

Si o imposto sobre a renda é um imposto complementar, devendo ser, por consequencia, um imposto mais leve, como se comprehende que possa ser cumulativo da União, e dos Estados, e se sobreponha, ainda, aos demais impostos directos?

Oue imposto meramente complementar é esse que vem pesar, assim, formidavelmente, sobre todas as rendas já tributadas e de um modo muito mais gravoso que todos os outros?

Por outro lado: se esse imposto, como reconhece a propria Commissão, «superpõe-se a quaesquer outras taxas, DE DENOMINAÇÕES DIVERSAS, que jä oneram as rendas»;

se, ainda na phrase da Commissão, "sem indagar da procedencia, attinge aos lucros da propriedade e da riqueza nas suas varias modalidades - MOVEL OU IMMOVEL, RURAL OU URBANA; Se é «Um tributo geral sobre os proventos da propriedade, da industria, das profissões, do commercio e dos officios»;

como é possivel, sem a mais imperdoavel contradicção, attribuil-o á União, deante do texto, de transparencia crystalina, do art. 9. ${ }^{\circ}$ da Constituição, que indicou esses objectivos á tributação exclusiva dos Estados?

$\mathrm{Si}$, com esse polvo, imposto de renda, póde a União taxar, como quizer, na proporção que bem the 
parecer, as industrias e os immoveis ruraes e urbanos, que significação tem esse artigo 9. ? E' possivel conceber como da esphera de exclusiva tributação dos Estados, materias que a União tambem póde gravar?

Que valor tem essa chamada discriminação de rendas, se, com qualquer sophisma descomposto, as commissões de orçamento a subvertem, para, satisfazendo sua vaidade, augmentarem as cifras da receita?

A proposito de um recente projecto de imposto sobre a renda, apresentado ás Camaras pelo governo francez, dizia no Petit Fournal (de I 7 de Julho d'este anno, I. columna) um eminente jornalista, Thomaz Grimm, estas palavras, que bem merecem a attenção da nossa Commissão de orçamento:

«Le gouvernement, on le sait, a déposé sur le bureau de la Chambre un projet d'impôt sur le revenu. Nous avons donc à renseigner nos lecteurs sur cet événement financier et politique.

«Ne soyons pas dupes des mots et des étiquettes. On pourrait croire qu'il s'agit là une nouveauté. En fait, le bon sens nous indique que tous les impôts atteignent nos revenus. L'impôt foncier est une taxe sur le revenu des propriétaires.

«La patente est une contribution imposée à tous ceux qui tirent un revenu du commerce, de l'industrie ou même d'une profession libérale, comme les avocats, les architectes, les médecins, les notaires ou les avoués; etc.

«Soyons donc sincères et disons la vérité: le revenu des citoyens est déjà 
frappé, diminue, confisqué de mille façons différentes.

«Il est question, aujourd'hui, de taxer le revenu d'une autre façon; voilà tout. C'est une étiquette, une formule nouvelle. Cela s'appelle impôt sur le revenu, mais rien n'est changé.»

Esta expressiva licção, que parece ter sido formulada para os financeiros e constitucionalistas do Congresso brasileiro, foi publicada na França, onde não se está adstricto «ao systema da mais rigorosa discriminação» como é o da nossa Constituição, na phrase da propria Commissão do Congresso.

Mas, esse «rigoroso systema de discriminação» é, de certo, para a Commissão, uma d'essas muitas nugas em que se não devem embaraçar os apertos orçamentarios da União.

Tanto que, para defender o seu parecer, diz ainda ella:

«Entre nós, já a celebre Commissão de I883, fazendo a discriminação das rendas geraes, provinciaes e municipaes, transferia ás Provincias o imposto de industrias e profissões; mas, compensando o desfalque que esta concessão acarretava ao Thesouro, dava ao centro o direito de tributar a renda e no projecto, que então formulou, figurava, o imposto de $2 \%$ sobre «os proventos ou lucros industriaes, commerciaes, ou de outra natureza e proveniencia, juros de lettras ou depositos em banco e caixas economicas, de sommas emprestadas a particulares, acções de compa- 
nhias, salarios ganhos, percepções pessoaes a titulo de industria ou trabalho.»

Entretanto a qualquer espirito reflectido, e livre das conveniencias de occasião, occorre, immediatamente, esta consideração, de procedencia irrecusavel: a commissão de 1883 tratava de estabelecer um systema de impostos; podia modelal-o como melhor lhe parecesse, mesmo creando uma competencia cumulativa sobre certas materias tributaveis. A situação hoje é, porém, inteiramente diversa; o systema, já prescripto na Constituição, é, absolutamente, outro; é um «systema de rigorosa discriminação» de materias tributaveis; e ninguem dirá, de boa fé, que não se enquadre Rigorosamente no art. $90^{\circ} \S 4 .^{\circ}$ da Constituição um imposto de $2 \%$ «sobre os proventos ou lucros industriaes, commerciaes de acções de companhias, salarios ganhos, percepções pessoaes a titulo de industria ou trabalho.»

Achará a Commissão que póde a União decretar hoje um imposto n'estes termos?

Eis ahi, medida com justeza, a força do raciocinio dos que procuram servir cegamente a conveniencias do momento e que preferem violar abertamente a Constituição a pedir a sua revisão.

S. Paulo-Dezembro I 903.

Dr. TRanoel Bedro Willaboim. 